\title{
Seed Micromorphology of Orthosiphon spp. and Its Relatives (Lamiaceae)
}

\begin{abstract}
Sudarmono
Research Center for Plant Conservation and Botanic Gardens - LIPI

Kebun Raya Bogor Jl. Ir. H. Juanda 13 Bogor

*Corresponding author. Email: paksudarmono154@gmail.com

ABSTRACT

The genus Orthosiphon in the Lamiaceae or Mint family is closely related to Ocimum and is economically important for medicinal and ornamental plants. Even though the leaf and flower morphology look different, but the characteristics of the seeds (nutlets) are almost the same. This study aims to determine the micromorphological character of the Orthosiphon seeds using a Scanning Electron Microscope (SEM). Observation of seeds apart from using SEM also with light microscopy on four taxa of Orthosiphon spp (Orthosiphon aristatus with pink flower, $O$. aristatus with white flower, $O$. endanghidayatae sp. nov., $O$. radjaampatensis sp. nov. and two taxa of Ocimum (O. canum and $O$. basilicum) as comparisons of their close relatives in the Lamiaceae. The largest seed size in $O$. aristatus with purple flowers $(2727 \mu \mathrm{m} \times 1364 \mu \mathrm{m})$ was elliptic oblong and the smallest size was $O$. hidayatae $(2182 \mu \mathrm{m} \times 1591 \mu \mathrm{m}$ in the oblong shape), while the color of the seeds was from blackish brown to black. A detailed explanation of the surface of the seeds, whether or not trichomes, the characters at the end of the seed axis are described in this paper. The evolution of the main seed characters in Orthosiphon is also discussed.
\end{abstract}

Keywords: micromorphology, seeds, Orthosiphon

\section{INTRODUCTION}

Plant systematics in general use morphological characteristics to classify their diversity into taxonomic subunits. Plant morphological variations usually use these characteristics to deduce the basics of morphological group division regardless of their systematic relationship. The characteristics of certain plant organs can be found in other organs that are usually smaller or finer in size, such as hair (pilus), scales (lepis), and lenticels (lenticulus) which are called micromorphology or additional complementary organs (organa accessoria). Together with the morphological characteristics of stems, leaf stalks and leaf anatomy, the types and distribution of trichomes, pollen and micromorphology of seeds or nutlets are important in the systematics of Salvia, a member of the Lamiaceae family [1]; [2]; [3], [4], [5]; [6], [7]. However, the seed structure or mericarp and trichomes of most species have not been studied. The micromorphology of the mericarp or seed and distribution of trichomes was studied for the first time to understand the usefulness of these characteristics for systematic purposes. Scanning Electron Microscope (SEM) studies of the seeds have revealed that they are round-spheroidal and exine oblate with perforated reticular ornament commonly. The seeds are the ovate area for fat, and the surface of the sculpting pattern is verrucate or slightly reticulated. Research from [8] that the surface micromorphology of leaves and seeds in 12 species of 6 members in the genus Teucrium L. was observed using scanning electron microscopy (SEM) provides information about the existence of kinship between members of the Lamiaceae family.

This study aims to determine the micromorphological character of the Orthosiphon seeds using a Scanning Electron Microscope (SEM)

\section{MATERIALS AND METHODS}

\subsection{Sample Collected}

This activity was carried out with samples of 
Orthosiphon spp. and Ocimum spp. All Lamiaceae member cultivated in Bogor Botanic Gardens, Bogor, West Java, then continued at the SEM Laboratory in Research Center for Biology, Cibinong Science Center, Cibinong, Bogor. Observations were made on the fruit of Orthosiphon spp. (Orthosiphon aristatus "pink flower", collected from Central Kalimantan, Orthosiphon aristatus "white Flower", Orthosiphon sp. nov collected from Waigeo island, West Papua, Orthosiphon sp. nov. collected from West Java), Ocimum basilicum and Ocimum canum.

\subsection{Seed Observations}

In addition, other characters are considered as characters that stand out from the observation such as the fur on the surface of the seeds. Seed specimens were taken in duplicate for each type of plant which was labeled accord- ing to the collection number. Each seed specimen must be whole and clean. Preparation using $70 \%$ ethanol fixation and affixed to the plate and vacuum until clean and dry. Furthermore, using Hitachi SEM, detailed morphology was observed. Observations were made in 2018 .

\section{RESULT AND DISCUSSION}

Botanical description on Orthosiphon plants are shrubs that grow to a height of $1.5 \mathrm{~m}$. Orthosiphon aristatus is a plant that is popular both as a traditional medicine and as an ornamental plant. The flowers are white or purple with a stamen and a pistil stalk extending out of the corolla to resemble a cat's whiskers. O. aristatus "pink flower" was collected from Central Kalimantan (accession number BO0017329), see figure 1(A). Habitus is shrub by $1.0-$
$1.5 \mathrm{~m}$ high. Leaves is simple, obovate, acuterhomboid - ovate, crenate - serrate. Inflorescences, terminal, corolla labiate by color is pink. Seeds in figure 2(A). Seed or nutlet shape is elliptic oblong, bald and blackish brown by size $2727 \mu \mathrm{m}$ x $1364 \mu \mathrm{m}$ (Table 1). There is no hair. O. aristatus "white flower" was collected from Bogor, West Java. See figure 1(B). Shrub is $1.0-1.5 \mathrm{~m}$ in high. Leaves are simple, obovate, acute-rhomboid - ovate, crenate serrate. Inflorescences is terminal, 13-15 nodes, 5-6 flowers per node $12.4 \mathrm{~cm}$ Corolla is labiate, pinkish white. Seeds are in figure 2(B). Nutlets shape are ovate, bald and blackish brown, $2227 \mu \mathrm{m}$ x $1227 \mu \mathrm{m}$ in size, oblong (Table 1). There is no hair. Orthosiphon sp. nov was collected from Waigeo island, West papua BO-18 82360 - West Papua, Sorong, Raja Ampat islands, Waigeo island, 50-66 m, 27/04/2008, collected by Sudarmono, H. Okada, H. Tsukaya. See in figure $1(\mathrm{C})$. Shrub by high $60-120$ $\mathrm{cm}$, and leaves are simple, ovate, acute, serrate - sub serrate. Inflorescence is terminal, 5-12 nodes, 5-6 flowers per node. Corolla shape is labiate, pinkish white. See seeds in figure $2(\mathrm{C})$ are nutlets shape as ovoid, bare and black, $2272 \mu \mathrm{m} \times 1682 \mu \mathrm{m}$ in size, oblong. There is no hair. Orthosiphon sp. nov. was collected from West Java, see figure 1(D). Leaves are simple, ovate, acute, serrate - sub serrate. Inflorescence is terminal, 9-14.7 cm, 14-16 nodes, 5-6 flowers per node. Corolla is labiate, pinkish white. See seeds in figure 2(D). Nutlets shape are ovate, and surface are verrucate pattern and blackish brown, $2182 \mu \mathrm{m} \times 1591 \mu \mathrm{m}$ in size, oblong (table 1). No hairs or few of hair in apex. Observations on the nutlets of all four taxa are almost ovate and hairless. Only on $O$. sp. nov.. from West Papua, which has little hair on the edges. But in both Ocimum have brown color and hair in an apex of seed.

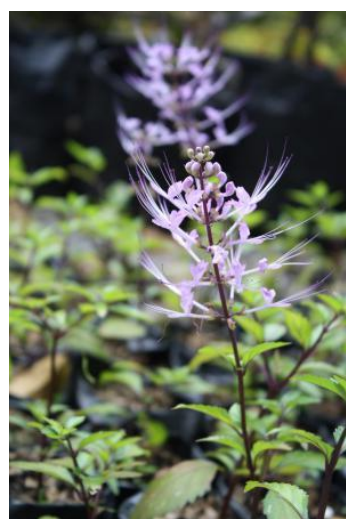

A

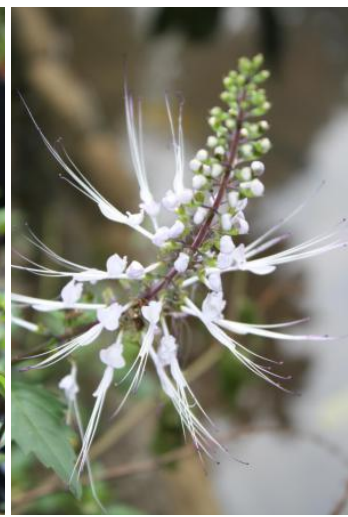

B

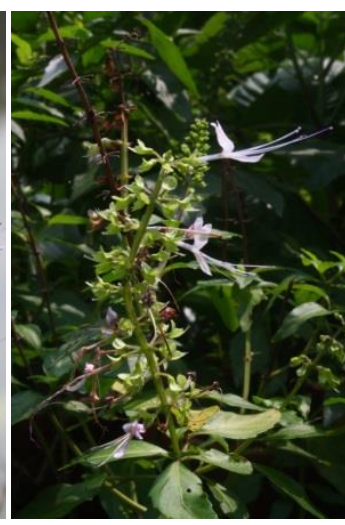

C

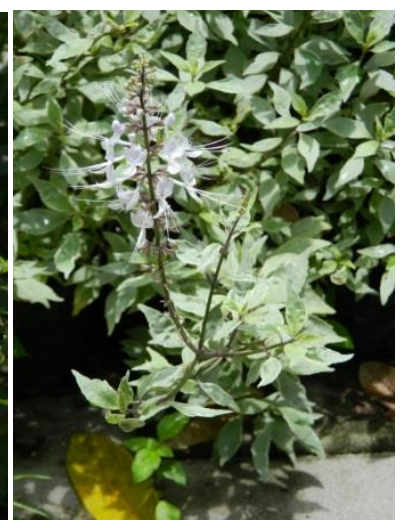

D

Figure 1. Left to right, four taxa in this tudy i.e. Orthosiphon aristatus "pink flower" (A), . O. aristatus "white flower" (B), O. radjaampatensis sp. nov (C) and $O$. endanghidayatae sp. nov. (D). 
A

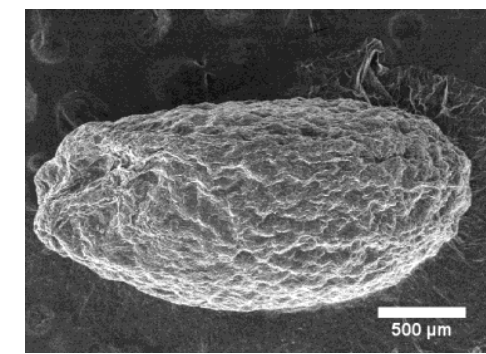

B

C

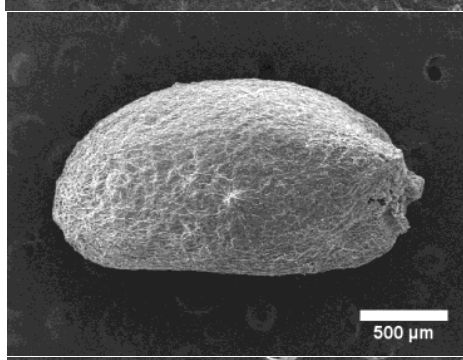

D

$\mathbf{E}$
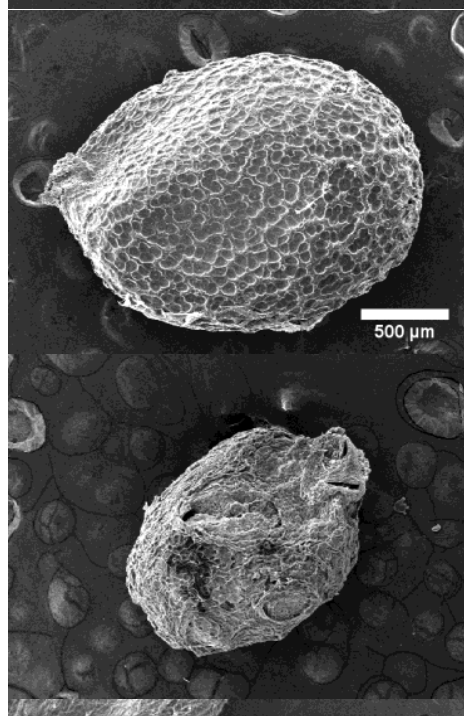

$\mathbf{F}$

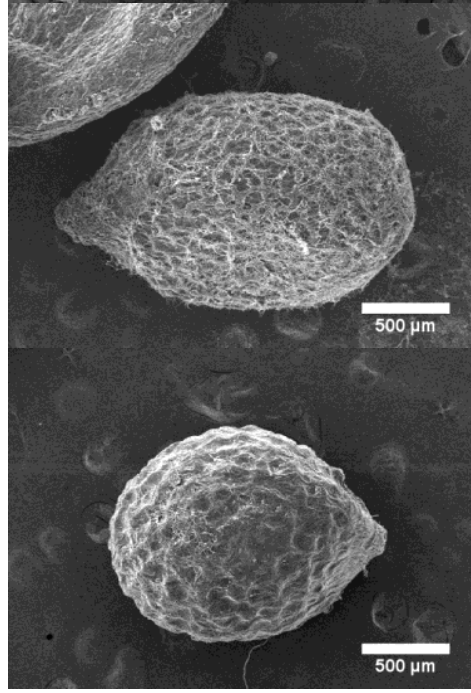

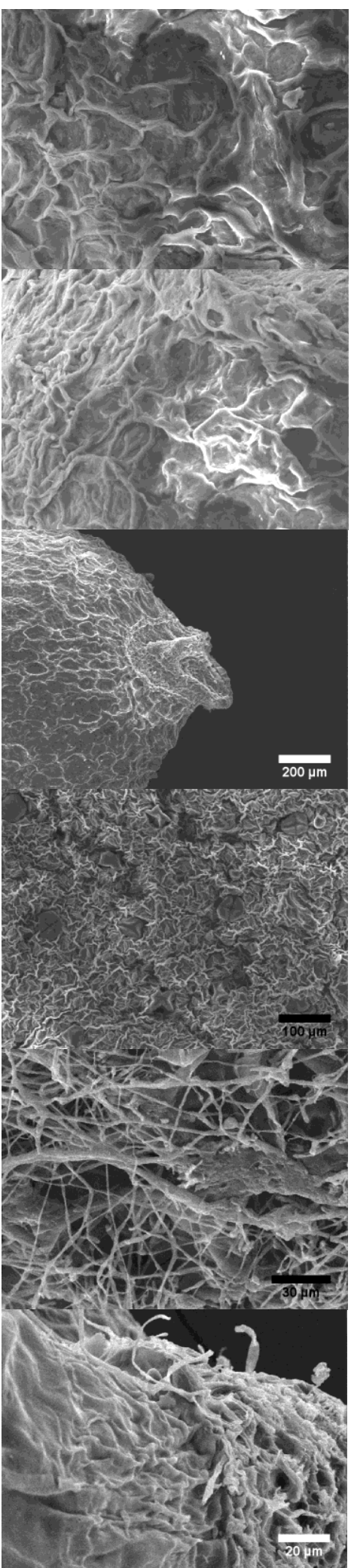

Figure 2. Seeds micromorphology at Orthosiphon aristatus "pink flower" (A), O. aristatus "white flower" (B), $O$. radjaampatensis sp. nov (C) and $O$. endanghidayatae sp. nov. (D). Ocimum basilicum (E), O. canum (F). The size follows the pictures below the scale line in each image. 
Table 1. Seed micromorphology of four Orthosiphon and two Ocimum taxa

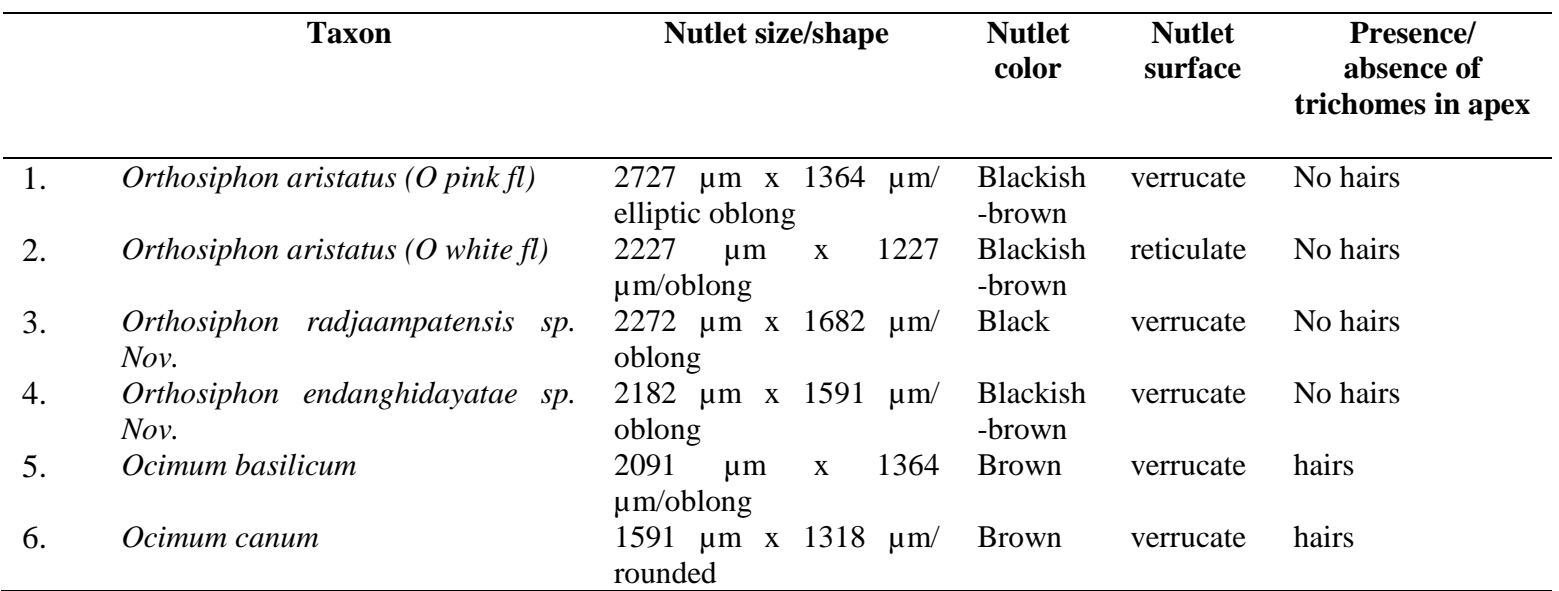

From the table 1, that the largest seed size in $O$. aristatus with purple flowers was $2727 \mu \mathrm{m} \times 1364$ $\mu \mathrm{m}$ or $2.7 \mathrm{~mm} \times 1.4 \mathrm{~mm}$, shape was elliptic oblong and the smallest size was $O$. hidayatae was $2182 \mu \mathrm{m}$ $\mathrm{x} 1591 \mu \mathrm{m}$ or $2.2 \mathrm{~mm} \times 1.6 \mathrm{~mm}$ in the oblong shape, while the color of the seeds was from blackish brown to black. Reticulate in surface is finely reticulate, there is in Orthosiphon aristatus "white flower" seed only (figure 2B). Verrucate in surface of seed is with irregular projections or knobs, i.e. in Orthosiphon aristatus "pink flower" figure 2(A), $O$. radjaampatensis sp. nov figure $2(\mathrm{C})$ and $O$. endanghidayatae sp. nov. figure 2(D).

Scientific classification in the family Lamiaceae or Labiatae (Mint Family) of the order Lamiales, i.e. one of the subfamily Lamiaceae, namely Nepetoideae, has the tribe Ocimeae and sub-tribe Ociminae. According to [9], which for Southeast Asia was revised on four genera including Basilicum, Orthosiphon, Ocimum and Platostoma. Orthosiphon has a close relationship with Ocimum with similar morphological features on its stems, flowers and seeds. [10] concluded that he nutlet morphology of 11 taxa of Mentha spp. distributed throughout Turkey was broadly oblong or ovoid. The Mentha taxa studied can be divided into three groups, based on nut sculpturing type such as distinctly bireticulate, inconspicuously bireticulate and reticulate. Based on the data of seeds then the systematic value of four taxa Orthosiphon morphology features can to evaluate relationship of Ocimeae tribe member of Lamiaceae.

\section{CONCLUSION}

The seed micromorphology of four taxa Orthosiphon spp. and two taxa of Ocimum spp,
Lamiaceae family members to be similar in size to each other. The largest seed size in $O$. aristatus with purple flowers was $2727 \mu \mathrm{m}$ x $1364 \mu \mathrm{m}$ (shape was elliptic oblong) and the smallest size was $O$. hidayatae was $2182 \mu \mathrm{m} \times 1591 \mu \mathrm{m}$ (oblong shape), while the color of the Orthosiphon seeds was from blackish brown to black. Seed surface is reticulate in Orthosiphon aristatus "white flower" seed only and verrucate in surface of seed in $O$. aristatus "pink flower", $O$. radjaampatensis $\mathrm{sp}$. nov and $O$. endanghidayatae sp. nov. Seed of four taxa Orthosiphon has no hairs, but hairy in Ocimum taxa seeds.

Seeds micromorphology in four taxa of Orthosiphon and two taxa of Ocimum in Nepetoideae tribe (Lamiaceae) can determine relationship both genera in Lamiaceae.

\section{ACKNOWLEDGMENT}

Our gratitude goes to the Head of Centre for Plant Conservation - Bogor Botanic Gardens - LIPI, who through the In-House Research Program 2017-2018 provided funds for the research. We would like to express my gratitude to Dr. Kartika Dewi, Sri Wahyuni, Zoology Laboratory - Cibinong Science Center, and also to all colleagues in the nursery of Gedung IX Bogor Botanical Gardens which are very helpfull during the research

\section{REFERENCES}

[1] E.S. Chakalova, E.M. Genova, N.T. Thuy, Comparative anatomical investigations on leaves of Salvia offificinalis L. and S. tomentosa Mill., Fitologija (46) (1993) 3-11.

[2] D.M. Henderson, H. Prentice, I.C. Hedge, Pollen 
morphology of Salvia and some related genera, Grana Palynol (8) (1968) 70-85

[3] A. Kahraman, F. Celep, M. Dogan, Comparative morphology, anatomy and palynology of two Salvia L. species (Lamiaceae), Bangladesh Journal of Plant Taxonomy (16) (2009) 73-82. DOI:10.3329/bjpt.v16i1.2749.

[4] A. Kahraman, F. Celep, M. Dogan, Anatomy, trichome morphology and palynology of Salvia chrysophylla Stapf (Lamiaceae), South Africa Journal of Botany (76) (2010) 187-195. DOI:10.1016/j.sajb.2009.10.003.

[5] P.D. Marin, S. Duletic, B. Petkovic, Nutlet ornamentation in selected Salvia L. species (Lamiaceae), Flora Mediterranea 61996 203211.

[6] H. O“zler, S. Pehlivan, A. Kahraman, M. Dogaan, F. Celep, B. Bas,er, A. Yavru, S. Bagherpour, Pollen morphology of the genus Salvia L. (Lamiaceae) in Turkey, Flora (206) (2011) 316-327.
[7] H. O־zler, S. Pehliva, F. Celep, M. Dog־an, A. Kahraman, A.Y. Fis,ne, B. Bas,er, S. Bagherpour, Pollen morphology of Hymenosphace and Aethiopis sections of the genus Salvia (Lamiaceae) in Turkey, Turkey Journal of Botany (37) (2013) 1070-1084. DOI:10.3906/bot-1209-50.

[8] M. Eshratifar, F. Attar, K. Mahdigholi, Micromorphological studies on nutlet and leaf indumentum of genus Teucrium L. (Lamiaceae) in Iran, Turkey Journal of Botany (35) (2011) 25-35. DOI:10.3906/bot-0902-5.

[9] S. Suddee, A.J. Paton, J.A.N. Parnell, Taxonomic revision of the tribe Ocimeae Dumort (Lamiaceae) in continental South East Asia III. Ociminae. Kew Bulletin (60) (2005) 375.

[10] G. Tarimcilar, Ö. Yilmaz, R. Daskin, G. Kaynak, Nutlet morphology and its taxonomic significance in the genus Mentha L. (Lamiaceae) from Turkey, Bangladesh Journal of Plant Taxonomy (20)1 (2013) 9-18. 